\title{
A New Concept in Relation to Blood Biochemical Parameters with Myocardial Infarction in Bangladeshi Population
}

\author{
S Zareen, ${ }^{1}$ M Badiuzzaman, ${ }^{2}$ SN Uddin, ${ }^{1}$ K Choudhury, ${ }^{1}$ SK Saha. ${ }^{1}$ \\ ${ }^{1}$ National Center for Control of Rheumatic Fever and Heart Diseases,Dhaka, ${ }^{2}$ National Heart \\ Foundation Hospital and Research Institute, Dhaka.
}

Key words:

myocardial

infarction, hypertriglyceridemia, hypercholesterolemia, bilirubin.

\begin{abstract}
:
Background : Blood testing for biochemical markers of Myocardial injury plays an increasingly important role for the evaluation, diagnosis and triage of patients with chest pain. The guidelines for the diagnosis of Myocardial Infarction ((MI) have recently changed and prominently incorporate the results of cardiac marker testing in the clinical definition of MI. We investigated these updated biomarkers and further compare the differing biology and release kinetics of clinically relevant biomarkers.

Methods: Biochemical changes that occurred in the blood of acute myocardial infarction (AMI) patients were investigated. Two hundred and fifty two patients, 180 males and 72 females were included in this study. The mean age was $49.3 \pm 9.25$ years. Biochemical parameters include serum triglyceride, total protein, albumin, total bilirubin and total cholesterol to albumin ratio were analyzed.

Results : Biochemical parameters showed that the increased level of triglyceride and total bilirubin were associated with myocardial infarction. Triglyceride and total bilirubin levels in myocardial infarction patients were $2.3 \pm 1.4 \mathrm{mmol} / \mathrm{L}$ and $12.3 \pm 3.2 \mu \mathrm{mol} / \mathrm{L}$ respectively, whereas those of healthy controls were $1.7 \pm 1.2 \mathrm{mmol} / \mathrm{L}$ for triglycerides and $9.7 \pm 3.7 \mu \mathrm{mol} / \mathrm{L}$ for bilirubin. On the other hand, serum total protein and albumin concentrations were lower in MI patients compared to those of controls. Total protein level was $65.5 \pm 3.1 \mathrm{~g} / \mathrm{L}$ in $M I$ patients and $76.2 \pm 5.3 \mathrm{~g} / \mathrm{L}$ in healthy controls. Albumin levels in both patients and controls were $40.2 \pm 3.2 \mathrm{~g} / \mathrm{L}$ and $45.4 \pm 4.5 \mathrm{~g} / \mathrm{L}$ correspondingly.

Conclusion : Interestingly, serum total cholesterol level was not significantly different in MI patients compared to controls. In addition, cholesterol/albumin ratio in myocardial infarction patients $(0.14 \pm$ $0.04)$ found to be significantly higher than in healthy controls $(0.11 \pm 0.03)$.
\end{abstract}

(Cardiovasc. j. 2013; 6(1): 43-46)

\section{Introduction:}

It is ironic for the heart, an organ that pumps several liters of blood each minute; itself suffers from lack of blood supply. Coronary heart disease (CHD) is commonly caused by atherosclerosis and plaque formation on the inner surface of the coronary arteries. These pathological factors cause narrowing of the major coronary arteries and thus decrease blood flow to the heart muscles. ${ }^{1}$ According to the American Heart Association, coronary heart disease causes 12 million deaths in world each year. CHD is responsible for half of deaths in several developed countries, and one of the main cause of death in adults in many developing countries. ${ }^{2}$ Premature death rates from CHD range from 40.5 per 100000 in France to 248 per 100000 in
Latvia, a ratio of 1: 6 globally. ${ }^{3,4}$ In Africa, Western Asia and Southeast Asia, 15-20 \% of the estimated 20 million annual deaths are due to coronary heart disease .5,6 Cardiovascular diseases are emerging as a major health problem in our country also. The portion of deaths ranges from 25-45 \%. ${ }^{7}$ High blood triglycerides and cholesterol levels were reported as risk factors of coronary heart diseases in many countries .7, 8 Developing countries have experienced rapid socioeconomic changes over the last two decades. Daily caloric intake has increased, which resulted in obesity. A high prevalence of smoking was reported among patients having acute myocardial infarction. ${ }^{9,10}$ Moreover, diabetes mellitus and hypercholesterolemia were implicated as risk factors, but there is no direct

Address of correspondence: Dr Salma Zareen, Associate Professor of Microbiology. National Center for Control of Rheumatic Fever and Heart Diseases (NCCRF \& HD), Shere Bangla Nagar, Dhaka, Bangladesh. 
evidence that either of these factors can adequately explain the increased vulnerability to coronary heart disease. ${ }^{11,12}$

Although, coronary heart disease is the leading cause of death in developed countries, developing countries such as Bangladesh has noticed an increase in deaths related to CHD. Risk factors such as obesity, smoking, low physical activities and unhealthy life-style have been observed in our country also. This increase is probably due to westernization that unmasks a genetic predisposition of Bangladeshi population for coronary heart disease.

The aim of this study is to investigate some blood biochemical parameters that are associated with myocardial infarction (MI) in Bangladesh. These include blood triglyceride, cholesterol, serum total protein, albumin, total bilirubin and total cholesterol to albumin ratio.

\section{Study Methods:}

This is a case-control study of patients with first attack of acute myocardial infarction (AMI) and age and sex matched controls. Biochemical parameters were obtained from the case files of patients with acute myocardial infarction admitted to the National Heart Foundation Hospital And Research Institute, Mirpur, Dhaka between January to December 2011.These cases were diagnosed on the basis of clinical symptoms, electrcardiography (ECG) and laboratory finding on the first day of admission. Only patients with complete biochemical data were included in the study. Healthy non-obese (BMI <25) subjects of same age and sex without any previous history of chest pain or myocardial infarction who visited the outpatient department (OPD) for minor ailments or routine medical checkup in the Shaheed Sohrawardy Hospital, Shere Bangla Nagar, Dhaka were chosen as controls. Biochemical tests for controls were done by commercial kits (Randox, UK) in the laboratory of NCCRF \& HD.

We applied simple descriptive statistics (mean and standard deviation) to describe our observations in both patients and controls. Statistical analyses were done on SPSS (version 6.0 ) and p-values $<0.05$ were considered significant.

\section{Results:}

Biochemical data were collected from 252 myocardial infarction (MI) patients of which 180 (71.43\%) were males and $72(28.57 \%)$ were females. The mean age of the participants in this study was $49 \pm 9.24$ years.

\section{Table-II}

Blood Total Protein, Albumin and Cholesterol to Albumin ratio in study population.

\begin{tabular}{lccc}
\hline Study population & $\begin{array}{c}\text { Total Protein } \\
(\mathrm{g} / \mathrm{L})\end{array}$ & $\begin{array}{c}\text { Albumin } \\
(\mathrm{g} / \mathrm{L})\end{array}$ & $\begin{array}{c}\text { Cholesterol to } \\
\text { Albumin ratio }\end{array}$ \\
\hline $\begin{array}{l}\text { Patients (mean } \pm 2 \text { SD }) \\
\mathrm{n}=252\end{array}$ & $65.5 \pm 3.1$ & $40.2 \pm 3.2$ & $0.14 \pm 0.04$ \\
$\begin{array}{l}\text { Healthy Control (mean } \pm 2 \mathrm{SD}) \\
\mathrm{n}=260\end{array}$ & $76.2 \pm 5.3$ & $45.4 \pm 4.5$ & $0.11 \pm 0.03$ \\
\hline$p$ - value & significant & significant & significant \\
\hline
\end{tabular}

Table-I

Blood Triglyceride, Total Cholesterol and Bilirubin level in patients and control group.

\begin{tabular}{lccc}
\hline Study population & $\begin{array}{c}\text { Triglyceride } \\
(\mathrm{mmol} / \mathrm{L})\end{array}$ & $\begin{array}{c}\text { Total Cholesterol } \\
(\mathrm{mmol} / \mathrm{L})\end{array}$ & $\begin{array}{c}\text { Total Bilirubin } \\
(\mu \mathrm{mol} / \mathrm{L})\end{array}$ \\
\hline $\begin{array}{l}\text { Patients (mean } \pm 2 \mathrm{SD}) \\
\mathrm{n}=252\end{array}$ & $2.3 \pm 1.4$ & $5.8 \pm 1.3$ & $12.3 \pm 3.2$ \\
$\begin{array}{l}\text { Healthy control (mean } \pm 2 \mathrm{SD}) \\
\mathrm{n}=260\end{array}$ & $1.7 \pm 1.2$ & $5.2 \pm 1.2$ & $9.7 \pm 3.7$ \\
\hline$p$ - value & significant & Not significant & significant \\
\hline
\end{tabular}


Table I demonstrated that blood triglycerides level in patients with MI $(2.3 \pm 1.4 \mathrm{mmol} / \mathrm{L})$ and in healthy control group is $(1.7 \pm 1.2 \mathrm{mmol} / \mathrm{L})$. Total cholesterol level in patients with MI as shown in table is $(5.8 \pm 1.3 \mathrm{mmol} / \mathrm{L})$ and in healthy individual is $(5.2 \pm 1.2 \mathrm{mmol} / \mathrm{L})$. Albumin and total protein levels in MI patients are $(40.2 \pm 3.2 \mathrm{~g} / \mathrm{L}$ and $65.5 \pm 3.1 \mathrm{~g} / \mathrm{L}$ ) respectively. As also seen in table II, total bilirubin concentration in Bangladeshi patients with MI and healthy control group are $(12.3 \pm 3.2 \mu \mathrm{mol} / \mathrm{L})$ and $(9.7 \pm$ $3.7 \mu \mathrm{mol} / \mathrm{L})$ respectively. Total cholesterol to albumin ratio in MI patients $(0.14 \pm 0.04)$ compared to healthy control $(0.11 \pm 0.03)$.

\section{Discussion:}

Myocardial infarction (MI) is emerging as a major health problem among the Bangladeshi population with male predominance. The mean age of the participants in this study was $49.3 \pm$ 9.25 years which is not significantly different from that has been previously reported by others

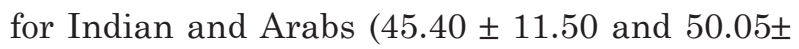
9.50 years), respectively. ${ }^{13}$ This suggests that myocardial infarction occurs at a similar age among Bangladeshi patients compared to other population.

High triglycerides (TG) blood levels that we found in MI patients are in agreement with what have been reported earlier by others. ${ }^{12}$ Previous findings suggested that hypertriglyceridemia predisposes to thrombosis by increasing factor VII coagulant activity and myocardial infarction should be considered in future studies. ${ }^{14}$ On the contrary, there is no significant differences in total cholesterol concentration between patients with MI $(5.8 \pm 1.3 \mathrm{mmol} / \mathrm{L})$ and control group $(5.2 \pm 1.2 \mathrm{mmol} / \mathrm{L})$. These observations suggest that high triglycerides but not cholesterol level in blood play an important role in myocardial infarction in our population (Table 1). Albumin and total protein concentrations in patients were significantly lower than those in control group (Table-2).These results are in agreement with what have been reported by Kuller et al who also found that there was a significant inverse relation between serum albumin level and risk of coronary heart disease. ${ }^{15}$

High total serum bilirubin levels in patients with MI may suggest that there is a direct correlation between total bilirubin and myocardial infarction. Our results are similar with those reported by Myer. ${ }^{16}$ Thus high serum bilirubin might be considered as a risk factor for myocardial infarction. On the other hand, Endler et al are not in agreement with our findings, who found that serum total bilirubin was an independent risk factor for myocardial infarction. Their report suggest an inverse relationship between bilirubin level and CHD; they stated that mild increase in the circulatory bilirubin might have a protective role against CHD by suppressing atherosclerosis. ${ }^{17}$ This protective mechanism might be inversed in the case of high plasma bilirubin levels as indicated by our study, where we have found a significant increase in these levels in CHD patients compared with controls.

Interestingly, we found that cholesterol-albumin ratio in blood is elevated in myocardial infarction patients compared with healthy controls. Our data confirm what has been reported previously by others. ${ }^{12-14}$ Therefore, cholesterol- albumin ratio should be considered as an indicator in coronary heart disease.

In conclusion, serum triglyceride levels, total bilirubin and cholesterol-albumin ratio were significantly higher in Bangladeshi population with myocardial infarction than those of the control group. Conversely, serum total protein and albumin level were low in the patients than in control group. No significant difference is found in serum cholesterol concentration between the two groups.

Therefore, serum triglyceride, bilirubin and cholesterol-albumin ratio may be considered as biochemical risk factors for coronary heart diseases (CHD) especially for myocardial infarction.

\section{Conclusion:}

Serum total cholesterol level was not significantly different in MI patients compared to controls. In addition, cholesterol/albumin ratio in myocardial infarction patients $(0.14 \pm 0.04)$ found to be significantly higher than in healthy controls $(0.11 \pm 0.03)$.

\section{Acknowledgements:}

We thank Dr MA Rouf and Dr Jasimuddin Ahmed from National Heart Foundation Hospital and Research Institute for their help in laboratory 
data collection and $\operatorname{Dr}$ M Mujibor Rahman,Director of Shaheed Sohrawardy Hospital and Medical college for his cooperation in selection and collection of samples from OPD.

\section{References:}

1. Iftikhar JK and Christie MB. Conditional risk factors for atherosclerosis. Mayo Clin Proc 2005; 80: 219-230.

2. American Heart Association. Heart and Stroke- a statistical update. 2001.http/www.american heart.org/ statistics/index.hotmail

3. Yusuf S. Hawkan S, Ounpue S et al. Effect of potentially modifiable risk factors associated with myocardial infarction in 52 countries: case-control study. Lancet 2004; 364: 936-967.

4. Olusi SO, Prabha K and Sugathan TN. Biochemical risk factors for myocardial infarction among South-Asian immigrants and Arabs. Saudi Med Journ 1999;19 : 147149.

5. Nusier MK, El-Akawi Z, Otoom SAK. Association of blood biochemical parameters with myocardial infarction. $J$ Health Science 2004;50(6): 666-669.

6. Enas EA and Senthilkumar A. Coronary artery disease in Asian Indians: an update and review. Int J Card 2002;1(2): 10-24.

7. Ramachandran A, Sathyamuthi I, Snehalata C et al. Risk variables for coronary artery disease in Asian-Indians. Am J Cardiol 2001;88: 201-202.

8. Casrelli WP. Lipid risk factors and ischaemic heart disease. Atherosclerosis 1996; 124: S1-S9.

9. Greenland P, Knoll MD, Stamler J, Neaton JD, Dyer AR et al. Major risk factors as antecedents of fatal and nonfatal coronary heart disease events. JAMA 2003;290: 891-897.
10. Gupta R, Gupta VP, Soma M et al. Prevalence of Coronary Artery Disease and risk factors in an urban Indian population. Ind Heart J 2002;54: 37-66.

11. Falcon C, Nespoli L, Geroldi D, Gazzaruso C, Buzzi MP et al. Silent myocardial infarction in diabetic and nondiabetic patients with Coronary Artery Disease. Int J Card 2003; 90:219-227.

12. Lindquist $\mathrm{P}$, Bengtsson C, Lissner L, Bjorkelund C. Cholesterol and triglyceride concentration as risk factors for myocardial infarction and death in women, with special reference to age. J Intern Med 2002; 251: 484-489.

13. Jappesen J, Hein HO, Suadicani P, Gytelberg F. Relation of high triglyceride, high density lipoprotein, low density lipoprotein and cholesterol to the incidence of ischaemic heart disease, atherosclerosis, thrombosis and vasculitis. J Bio 2005;85 :1-13.

14. Lien WP, Lai LP, Shyu KG, Hwang JJ, Chen JJ, Lei MH et al. Low serum high density lipoprotein cholesterol concentration is an important risk factor in Chinese patients with low serum levels of total cholesterol and triglycerides. Am J Cardiol 1996; 77: 1112-1115.

15. Kuller LH, Eichner JE, Orchard TJ, Granditis GA, McCallum L, Tracy RPP. The relation between serum albumin level and risk of coronary artery disease in the multiple risk factors interventional trial. Am J Epid 1991; $134: 1266-1277$.

16. Myer M. Association of serum bilirubin concentration with risk of coronary artery disease. Clin Chem 2003; 46 : 1723-1727.

17. Endler G, Hamwi A, Sunder-Plassmann R, Exner MM , Vukovich $\mathrm{T}$ et al. Is low serum bilirubin an independent risk factor for coronary artery disease in men but not in women? Clin Chem 2003; 49: 1201-1204. 